\title{
Verbal Art: From the Polyphony of the Word to Non-Verbality
}

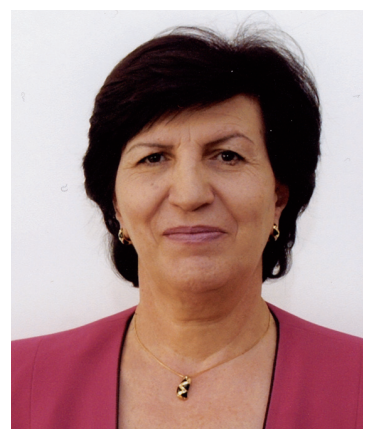

Seda Gasparyan

Theorists since Aristotle have argued that literature is not

mere entertainment, that the impulses to make poetry, to tell stories and express our feelings in words play a central part in our lives. Since ancient times attempts have been made to establish what literature in the proper sense of the word is.

It is our firm belief that to come closer to the answer of this question we have to look into the complex correlation of form and content. Literary form is known to carry out different functions the basic of which is to give pleasure. ${ }^{1}$ It is beyond suspicion, that everything in nature has its peculiar form and content. Content is the essence of a notion, its essential quality by which all the peculiar features of the notion are determined, whereas form is the sum of all the internal and external elements of the content, its way of exposure and existence. There is no form without content and there is no absolute content without a form. These two elements are interconnected and can never be separated, unless we separate them for methodological purposes. Thus, it is not by chance that for Hegel "content is the transference of form to content, and form is the transference of content to form". (Hegel, 1958)

From what has been said above it becomes clear that in verbal art pride of place should be given to the dialectical correlation of content and form which not infrequently results in ambiguity of literary works, multiple meanings and shades of meanings which are condensed and played upon in a work of verbal creativity, including the so-called below-the-surface meaning, the different additional expressive-emotional-evaluative overtones and associations attached to the linguistic elements in different historical periods and the meanings they may have for different readers. Thus, it can be stated, that verbal art is an artistic experience that realizes itself in the medium of language, which does not merely dress our thoughts but shapes and phrases them. ${ }^{2}$

It should be mentioned in this connection that all varieties of art are meant to make an impact on their addressees. This impact is often not only intellectual but also aesthetic, i.e. we do not only think of what we see but also feel it, as it moves us and causes excitement. Verbal art is the only type of art which creates its images exclusively with the help of human language. It is due to language that the writer manages to penetrate into every corner of human relationships and psychology, to raise important social problems and serve social ideals, to lead the reader to certain conclusions, change his inner world, help to find his right orientation in life. ${ }^{3}$

However, it has always been an uneasy task to decide what the linguistic means are with the help of which this kind of multifariousness of a work of verbal art is achieved. 
It has been established that every piece of writing which claims the title of verbal art is characterized by an original style which largely depends on the unusual way in which words, word-combinations and other linguistic units are chosen and brought together, thus helping the author to express his worldview, to convey his intentions of writing that particular piece of literature and bring it home to his readers what the global purport of the work is. In fact, every linguistic unit becomes an indispensable part of the author's conception and the scheme of his work.

Yet, however hard it might be to decide what peculiar features of the formal (linguistic) aspect of a literary work provide its multilateral nature research work along these lines has already established that among the great variety of linguistic means it is especially words that serve as the literary artist's basic tool to embody his unique, profound and beautiful visions.

In this respect, of course, it is the polyphony ${ }^{4}$ of the word that should be mentioned first of all as it is believed to be one of the most characteristic features of verbal creativity. (Gasparyan S.,2008)

Our assumption is that the term polyphony can be applied to a literary text because we believe that the main difference between literary texts and all other kinds of texts consists in the former being polyphonic. Thus, for instance, we can speak of thematic polyphony in a literary text because it is usually characterized by a complex intertwinement of various recurrent themes. ${ }^{5}$ Thematic polyphony brings about rhythmical and sound polyphony because different themes are supposed to have rhythmical and sound arrangements of their own. We can go so far as to speak of verbal polyphony - the polyphony of words and word-combinations.

Investigations have shown that the established opinion about a polysemantic word actualizing only one of its several meanings in each particular use holds true for intellective prose only. ${ }^{6}$ When what we deal with is a literary piece, the semantic boundaries of the word are extended and its semantic capacity is realized to the full. The word acquires additional connotative and associative meanings which are very closely linked together in the context of a literary work and evoke multitudes of thoughts, images and explanations. In other words, in works of verbal art words display the tendency of widening their semantic potential, acquiring additional depth and capacity and stimulating the creation of the global "image" of the word in which it is often impossible to pick out separate meanings. It actually appears as an indivisible global whole with all its latent semantic and stylistic potentialities realized simultaneously. Otherwise stated, when we deal with verbal art it is the global semantic structure of the word that comes first, and without this globality the word could not serve as the basic implement of verbal art. ${ }^{7}$ Here is an example picked out from "The Rainbow" by D.H.Lawrence:

\section{And Lydia, as if drugged, followed him like a shadow, serving, echoing.}

The role of the polyphonic actualization of the word shadow in the given context cannot be overestimated. All the different meanings of the word (dark shape thrown to the ground; sth. unsubstantial or unreal; smb. weakened, exhausted; faint representation of sth. or smb.; etc) presented in different dictionaries and the shades of meanings 
realized in different combinations of the noun shadow with other words (the shadow of death; the shadow of night; the shadow of misfortune; etc) are all condensed here to interpret the enormous power in which the personage - Paul Lensky, held his wife. It explains the hopelessness and "ignominy" of the state Lydia was helpless to cope with.

If we try to compare the context adduced above with, say, she was caught like a rat in a trap, it will not be difficult to notice that in the second context we deal with a battered simile in which the writer makes use of a ready-made lexicalized combination of words to suit his purpose whereas in the first case the simile is based on the psychological state the heroine is in. The complexity of the situation is conveyed with the help of the polyphonic word shadow.

It is against the background of what has been said above that the terms "verbal" and "non-verbal" can be introduced. They are meant to denote the basic difference between speech as creative art and speech which comes nearer to what is rational and matter-of-fact and is based on the speaker's ability to manipulate ready-made material.

It can be assumed that speech is creative art when it is marked by "non-verbality", for the essence of creativity is the emancipation from the bondage of ready-made, trivial, properly verbal expressions. In intellective communication "verbality" is indispensable for in this case speaking implies the ability of the speaker to choose this or that combination of words from among already existing ready-made ones.

The contexts adduced above show that the difference between "verbal" and "nonverbal" ways of saying things becomes even more obvious when we concern ourselves with "simile" which, as if transfigured in the literary context, becomes aesthetically significant and gives birth to various connotations and associations. Its metametasemiotic value is very closely connected with the ideological content of the work and the aesthetic position of the writer. Here are more examples:

Myself, my family, my generation were born in a world of silence, a world of hard work and necessary patience, of backs bent to the ground, hands massaging the crops, of waiting on weather and growth, of villages like ships in the empty landscapes and the long distances between them, ...

(L.Lee, Cider with Rosie)

The simile villages like ships in the empty landscapes and the long distances between them, ... in this context is poetic for objects from incompatible spheres (villages - ships) are brought together only due to the writer's imagination who with his mind's eye can observe a common implicit inner feature in the two objects compared. This non-verbal simile not only gives the reader an idea of how physically isolated those villages were but also creates a global poetic image which symbolizes the communicative isolation of people in that, by English standards, empty country. in air.

We kissed, once only, so dry and shy, it was like two leaves colliding

$$
\text { (L.Lee, Cider with Rosie) }
$$


The recurrent use of the lateral sonorant [1] in the simile stirs up the reader's imagination and he immediately gets the impression of something very light and imponderable floating very softly. The choice of the word collide in the simile, where a bashful kiss is compared to the rustling of the leaves in the air, has not been made at random. Its polyphonic actualization in this context conveys the spontaneously pleasant but at the same time embarrassing situation in which the teen-agers - the boy and the girl - found themselves when the first sensations of love crawled into their body and soul.

It should be added however that even in verbal art it is not always that simile arises from an imaginative or visionary association of things. Thus, for example,

And a man came up and kissed the girls and hopped in the road and twisted on one toe. Then he fell down in the mud and lay there, working his legs like a frog and croaking a loud song.

\section{(L.Lee, Cider with Rosie)}

This simile is obviously verbal as what we deal with is a very banal situation and the words used in the context and in the simile in particular are in one-to-one correspondence with the referents they denote. The reader has no difficulty in understanding the context. He can easily visualize the situation for the common feature chosen by the writer as basis for comparison is physical and easily perceived.

We can observe a similar picture in the following example as well:

You could put your head in the water, and open your eyes, and see the sides of the bucket buckle, and hear your caught breath roar, and work your mouth like a fish, and smell the lime from the ground.

$$
\text { (L.Lee, Cider with Rosie) }
$$

Here again the comparison is based on outer physical resemblance the understanding of which causes no difficulty to the reader. The words chosen by the writer are quite ordinary, completely devoid of any polyphonic qualities. They fit the writer's intention of describing the banality and triviality of the situation.

Thus, we can conclude that the opposition non-verbality vs verbality depends, to a great extent, on the polyphonic vs non-polyphonic actualization of words in verbal art.

\section{Notes:}

1. In Simon O. Lesser's opinion, literary form carries out three functions: to give pleasure, to avoid or relieve guilt or anxiety, and to facilitate the perception of the material with the desired degree of clarity, in fact, performing the role of a rational, organizing element. (Lesser S.O., 1957)

According to Sigmund Freud, literary form has the benefit of affording pleasure, making the text attractive to the reader and prompting him to take over the imaginative 
understanding of the world offered to him by the author. Form is, therefore, thought by him to provide an "incentive bonus", a "fore-pleasure". However S.Freud himself and his followers in the sphere of psychoanalytic literary criticism could see the ancillary role of form in verbal art and art in general for they were sure that the basic thing in literature is the imaginative content conveyed by the writer.

S.Freud believed that works of art in general and verbal art in particular express the artist's or the writer's "most secret mental impulses" through a peculiar kind of expression, transforming the unconscious into verbal or visual forms. (Freud S., 1960)

2. In fact, the writer himself cannot know what language he needs before the ideas germinating in his mind "are transformed into an arrangement of the right words in the right order". (Eliot T.S., 1969:97)

3. It is interesting to note that $\mathrm{Ch}$. Darwin at the end of his life felt really sorry for not having paid appropriate attention to arts, as he had devoted himself to science. He was more than sure that being at a great distance from arts "blunts" one's spiritual capacities. (Belinski V.G., 1954)

In Hugo Roeffaers' words "the production of meaning is open-ended" in literature as every piece of verbal art "creates its own context of signification, a context which is a-referential", and this is natural, as literature is not the factological representation but the specific, imaginative reverberation of the world, or, in other words, a fictional reality. (Roeffaers H., 2002)

4. Polyphony, as is well known, is a musical term meant to denote a form of musical composition in which a number of different independent parts are played simultaneously harmonizing together. (Bolshaya Sovetskaya Enciklopedia, 1975:227) It was by M.M.Bakhtin that the term was first applied to Dostoevski's works in which the "voices" of the author and the characters, equally independent, "sound" in harmony,. (Bakhtin M.M., 1972)

The term has been believed quite acceptable to reflect the multifareous nature and the semantic globality of the literary word, let alone its ability to "sound" variously (both in the proper sense of the word and metaphorically expressed) in the context of a literary work. (Gasparyan S., 2008)

The notion of the polyphony of the word approximates to what W.Empson describes as the semantic "pregnancy" of the word in a metaphoric context.(Empson W., 1967)

5. This aspect of word polyphony is discussed by Oyama Toshikazu who shows that the words monster/monstrous (Othello), nothing (King Lear), brave (The Tempest), etc. in Shakespeare's plays gradually acquire more and more new shades of meanings when intensively used in different situations by different personages and create a pivotal image uniting different thematic parts of the play into a global whole.(Toshikazu O., 1980)

6. The polysemy of the word is achieved naturally: the crystallization of the individual uses of the word results in the occurrence of new meanings, thus enhancing the development of word meaning in the system of language. This, in its turn, is conditioned by the changes in the material life of the society and the ideology domineering in it. (Vinogradov V.V., 1966; Budagov R.A., 1977) 
7. The polyphonic quality of the word, characteristic of the etic level of language, in a piece of verbal creativity becomes a key to the realization of the author's intention.

\section{References:}

1. Akhmanova, O., Zadornova, V. (1981) Speech, Pragmatics and Creativity // Logos Semanticos. Berlin.

2. Bakhtin, M.M. (1972) Problemi poetiki Dostoevskogo. Moskva: Khudozh. Lit.

3. Belinski, V.G. (1954) Pilisopayakan yntir yerker. Yerevan: Haypethrat. Vol. 1.

4. Budagov, R.A. (1977) Chto takoe razvitie i sovershenstvovanie yazika? Moskva: Nauka.

5. Eliot, T.S. (1969) The Sacred Wood. Essays on Poetry and Criticism. $7^{\text {th }}$ Edition. London: Methuen.

6. Empson, W. (1967) The Structure of Complex Words. Michigan University Press.

7. Freud, S. (1960) The Interpretation of Dreams. New York: Basic Book.

8. Gasparyan, S. (2008) Linguopoetika obraznogo sravneniya. Yerevan: Lusakn.

9. Hegel, G.V.F. (1958) Sochineniya. Moskva: Gos. Izd. Polit. Lit. Vol. XVI.

10. Lesser, O.Simon (1957) Fiction and Unconscious Experience. Boston, Massachusetts.

11. Roeffaers, H. (2002) Aesthetic Experience and Verbal Art. University of Antwerp.

12. Toshikazu, O. (1980) Shakespeare's Thematic Characterization // Shakespeare Translation. Tokyo. Vol. 7.

13. Vinogradov, V.V. (1966) Iz itorii russkikh slov $i$ virazheniy // Voprosi stilistiki. Moskva, MGU.

\section{Funwinltuun. puqưuămjanıpjnıling

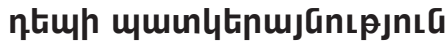

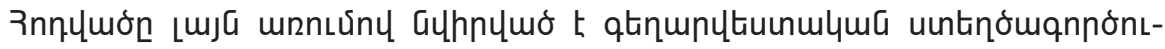

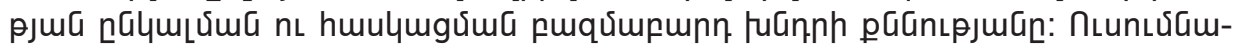

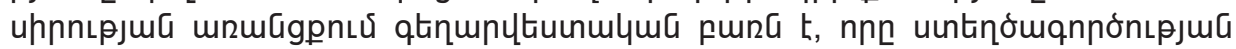

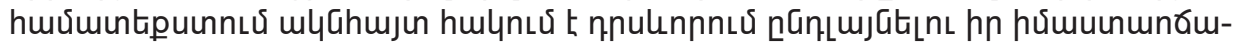

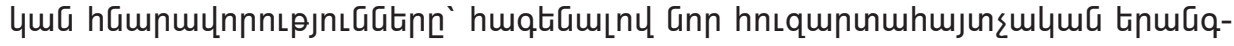

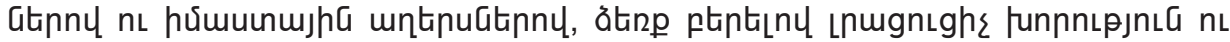

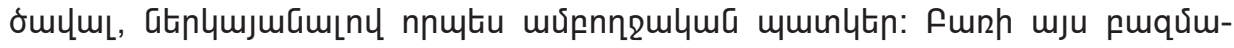

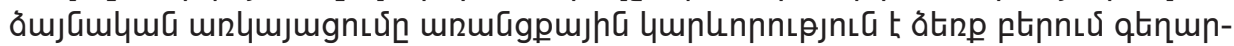

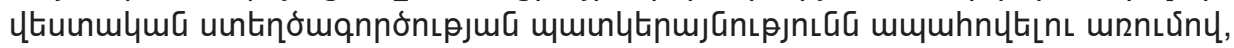

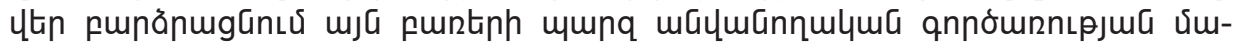

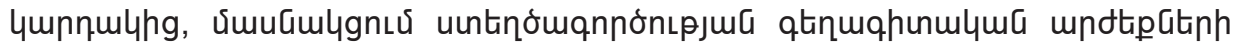

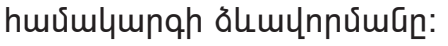

